\title{
DÍA MUNDIAL DEL GLAUCOMA
}

\author{
NOGUERA-PALÁU JJ ${ }^{1}$
}

El seis de marzo de 2008 se celebró el primer Día Mundial del Glaucoma por iniciativa de la Asociación Mundial del Glaucoma (WGA) y de la Asociación Mundial de los enfermos de Glaucoma (WGPA); en 2009 ha sido el 12 de marzo.

La Asociación Mundial del Glaucoma, a la que pertenece la Sociedad Española de Glaucoma, defiende la máxima calidad en los estudios y tratamientos del glaucoma mediante la comunicación y la cooperación entre las múltiples sociedades internacionales de glaucoma, industrias relacionadas, organizaciones de pacientes y cualesquiera otros grupos sociales; merced al impulso y patrocinio de aquella, en octubre de 2004 se creó la Asociación Mundial de enfermos de Glaucoma para procurar la
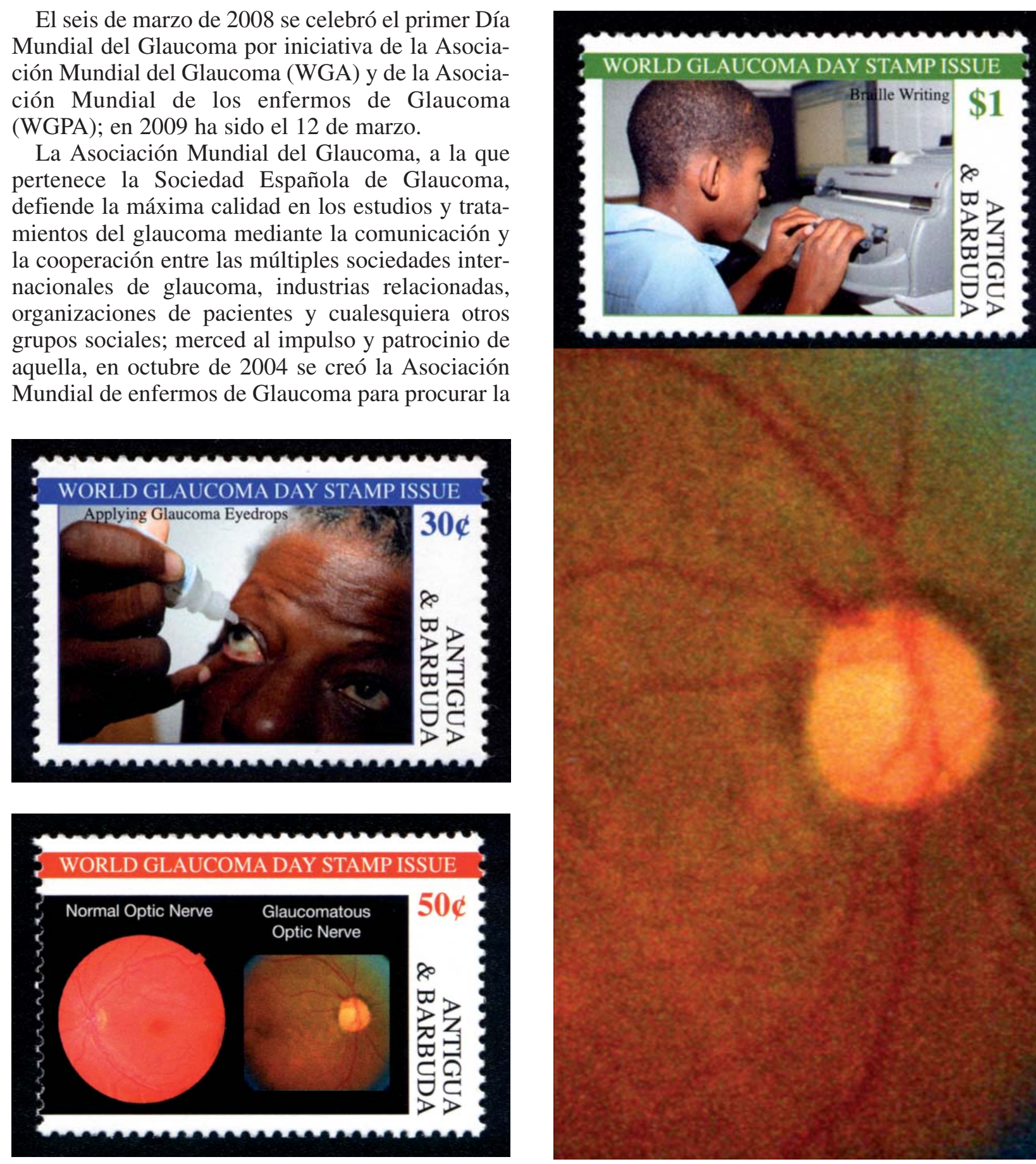

\footnotetext{
1 Oftalmólogo. Pamplona.

E-mail: jnoguera72b@terra.es
} 
mejor calidad de vida de estas personas mediante la cooperación entre las diversas organizaciones de todo el mundo y con la información precisa para el conocimiento y tratamiento de su enfermedad. En España, desde enero de 2005, existe con este fin la Asociación de Glaucoma para Afectados y Familiares (AGAF) con sede en Alcalá de Henares (Madrid).

Con motivo del primer Día Mundial del Glaucoma, los correos de Antigua y Barbuda, estado inde- pendiente en las Antillas Menores, al este del mar Caribe, emitieron la serie de tres sellos que ilustran esta nota (Yvert, 2008 - 3910/12). En el sello de $50 \notin$ se comparan una papila normal y otra glaucomatosa; se adjunta una ampliación de la glaucomatosa. En el sello de \$1 se muestra una máquina Perkins-Brailler ${ }^{\circledR}$ para escribir en el sistema braille.

En 2009 no se ha emitido ningún sello conmemorativo del suceso que da título a este artículo. 